Tropical Journal of Pharmaceutical Research September 2020; 19 (9): 1895-1901

ISSN: $1596-5996$ (print); 1596-9827 (electronic) (C) Pharmacotherapy Group, Faculty of Pharmacy, University of Benin, Benin City, 300001 Nigeria.

\title{
Phytochemical composition and pharmacological assessment of callus and parent plant of Asteriscus graveolens (Forssk.) Less. from Algerian Sahara
}

\author{
Fairouz Belhadi*, Saida Ouafi, Nadia Bouguedoura \\ Research Laboratory on Arid Zones (LRZA), Faculty of Biological Sciences, University of Sciences and Technology Houari \\ Boumediene, BP $n^{\circ} 32$ El-Alia, Bab Ezzouar, 16111 Algiers, Algeria
}

*For correspondence: Email: belhadifairouz@gmail.com

Sent for review: 19 January 2020

Revised accepted: 20 August 2020

\begin{abstract}
Purpose: To determine the phytochemical composition, acute toxicity, as well as analgesic and antiinflammatory properties of extracts of the aerial parts and callus cultures of Asteriscus graveolens.

Methods: Different standard chemical tests were used for the screening of bioactive compounds in aqueous extracts of aerial parts of Asteriscus graveolens (PAE) and callus (CAE). High-performance liquid chromatography (HPLC) analysis was performed to identify the constituents of the glycosidic extract (GE). Acute oral toxicity test was carried out to ascertain the safety of the plant material. The analgesic and anti-inflammatory properties of the extracts were determined using acetic acid-induced writhing test and carrageenan-induced edema test, respectively.

Results: Phytochemical analysis showed some differences in composition between the aerial parts and callus cultures. Results from HPLC analysis revealed the presence of 12 phenolic compounds in the GE of adult plants. In addition to being orally safe (no mortality), all extracts showed significant inhibition of acetic acid-induced chemical pain: PAE and GE produced 63 and $68 \%$ reductions in pain, respectively, relative to $60.26 \%$ pain reduction by aspirin. All extracts exerted potent anti-inflammatory effects, with PAE producing the highest effect (73\%) at a dose of $100 \mathrm{mg} / \mathrm{mL}$.

Conclusion: Asteriscus graveolens extracts possess potent pharmacological properties due to the presence of some phenolic compounds, especially flavonoids. These findings provide a scientific basis for the traditional uses of Asteriscus graveolens, and indicate that it is a potential source of antiinflammatory agents.
\end{abstract}

Keywords: Acute toxicity, Anti-nociceptive, Anti-inflammatory, Aqueous extract, Callus, Flavonoids

\begin{abstract}
This is an Open Access article that uses a fund-ing model which does not charge readers or their institutions for access and distributed under the terms of the Creative Commons Attribution License (http://creativecommons.org/licenses/by/4.0) and the Budapest Open Access Initiative (http://www.budapestopenaccessinitiative.org/read), which permit unrestricted use, distribution, and
\end{abstract} reproduction in any medium, provided the original work is properly credited.

Tropical Journal of Pharmaceutical Research is indexed by Science Citation Index (SciSearch), Scopus, International Pharmaceutical Abstract, Chemical Abstracts, Embase, Index Copernicus, EBSCO, African Index Medicus, JournalSeek, Journal Citation Reports/Science Edition, Directory of Open Access Journals (DOAJ), African Journal Online, Bioline International, Open-J-Gate and Pharmacy Abstracts

\section{INTRODUCTION}

The Algerian Sahara Desert is renowned for its large area and diverse flora. The Hoggar region contains about 300 plant species, and over a quarter of these species are considered as medicinal plants. A comprehensive knowledge of these species and their traditional uses would serve as a repertoire of unlimited sources of natural products.

Asteriscus graveolens (Forssk.) Less. belonging 
to the Asteraceae family is a perennial sub-shrub which is common in Algerian Sahara Desert [1]. It is locally named tamayout in Tamahaq language spoken in Southern Algeria, and is also referred to as nougued and tafss. The aerial parts of the plant are widely used by local population due to their aromatic and therapeutic properties. The plant is used as a traditional remedy for pain, gonorrhea, diabetes, hypertension, inflammation, fever, gastric and intestinal illnesses, and as a purgative [2,3].

The overexploitation of field-grown medicinal plants by local populations and herbal practitioners presents a serious threat to the survey of these plants. Therefore, the solution to this problem might lie in the development of a reliable in vitro-based protocol. The development of such techniques offers many advantages such as independence from environmental factors such as climatic and soil conditions, absence of biological influences, as well as decreases in cost and increases in the production of secondary metabolites with the aid of automated cell growth control and regulation of metabolic processes [4].

Studies have been carried out on the phytochemical composition of Asteriscus graveolens $[3,5,6]$. However, not much is known on the pharmacological properties of the plant. Moreover, no studies have been carried out on the possibility of establishing in vitro cultures of Asteriscus graveolens.

The aim of the present study was to investigate the analgesic and anti-inflammatory effects of the callus cultures and aerial parts Asteriscus graveolens. This was with a view to ascertaining whether the calluses have the same chemical composition and pharmacological properties as the mother plant, so as to provide a more convenient means of producing bioactive compounds from the plant via plant tissue culture techniques.

\section{EXPERIMENTAL}

\section{Animals}

The experiments were performed on Swiss albino mice (Mus musculus) of either sex, weighing $18-22 \mathrm{~g}$. The mice were provided by CRD-Saidal. Prior to the experiments, the mice were acclimatized for at least one week in plastic cages at $22 \pm 2{ }^{\circ} \mathrm{C}$ in an environment with a 12-h light/12-h dark cycle, and were permitted ad libitum access feed and water. The mice were fasted overnight prior to the start of the experiment. The experiments were carried out following international guidelines for animal studies [7].

\section{Plant materials}

Fresh plants and seeds of Asteriscus graveolens were collected from their native area in Tamanrasset (Southern Algeria) at flowering stage in March, 2013. This species was identified using a specimen in the herbarium Herbier

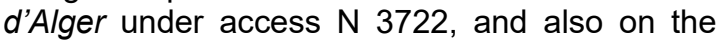
basis of the botanical description of Ozenda [2]. The aerial parts were air-dried in a shade at room temperature, and powdered with an electric grinder prior to use for preparation of different extracts. The seeds were used for callus production.

\section{Establishment of callus culture}

The seeds were surface-sterilized with $70 \%$ ethanol for $60 \mathrm{sec}$, followed by rinsing with sterile distilled water for $30 \mathrm{~min}$ to allow for good imbibition. They were then aseptically cultured on basic half-strength Murashige and Skoog agarsolidified medium until germination [8]. Just after germination, there was callus formation on the plantlet. The calluses were then transferred to agar-solidified MS medium supplemented with the growth regulators kinetin $(2 \mathrm{mg} / \mathrm{L})$ and ANA $(2 \mathrm{mg} / \mathrm{L})$ before autoclaving at $120^{\circ} \mathrm{C}$ for $20 \mathrm{~min}$. The calluses were then grown and maintained in a culture chamber at $25{ }^{\circ} \mathrm{C}$ in the dark. Friable callus cultures were used for further analysis.

\section{Preparation of test samples}

Infusion aqueous extracts were prepared from powdered aerial parts of Asteriscus graveolens and fresh callus cultures, resulting in plant aqueous extract (PAE) and fresh callus aqueous extract (CAE), respectively. The infusion extracts were prepared using a method exercised by the local herbal practitioners. The plant material (powdered aerial parts or fresh callus) was weighed and placed inside an appropriate volume of boiling saline for $20 \mathrm{~min}$ at room temperature. Thereafter, it was filtered with Whatman filter paper (No 1). The infusions were prepared at different doses just before administration to the animals in order to avoid any variations.

The glycosidic extract (GE) was prepared as follows: $2 \mathrm{~g}$ of plant powder was macerated for $48 \mathrm{~h}$ in $200 \mathrm{~mL}$ of $70 \%$ ethanol. The resultant mixture was filtered with Whatman No. 1 filter paper and concentrated under reduced pressure at $40{ }^{\circ} \mathrm{C}$ using a rotary evaporator. The residue was recovered with $100 \mathrm{~mL}$ of boiling distilled 
water. The aqueous solution was then extracted with $50 \mathrm{~mL}$ of $\mathrm{n}$-butanol, and the extract was concentrated under reduced pressure. The resultant residue was weighed and used for different tests.

\section{Phytochemical screening}

Plant aqueous extract (PAE, $10 \%$ ) and $10 \%$ CAE were subjected to different chemical tests using standard procedures as described by Trease and Evans [9] and Samejo [10]. The presence or absence of the phytochemical constituents i.e. flavonoids, glycosides, saponins, tannins, terpenoids and alkaloids were determined through the appearance of appropriate color changes in the various tests.

\section{HPLC analysis}

Analysis of the glycosidic extract (GE) was performed using Agilent HPLC 1100 (Agilent Technologies, Germany) equipped with Hypersil BDS-C18 column $(5 \mu \mathrm{m}, 250 \times 4.6 \mathrm{~mm})$ coupled to a UV detector with diode bars (DAD). The mobile phase comprised 2 solvents: acetic acid (eluent A) and acetonitrile (eluent B). A linear gradient program was used for $30 \mathrm{~min}$ at a flow rate of $1.5 \mathrm{~mL} / \mathrm{min}$, beginning from $95 \%$ aceticacid and ending with $100 \%$ acetonitrile. After filtration, $20 \mu \mathrm{L}$ of each sample was injected at a flow rate of $1 \mathrm{~mL} / \mathrm{min}$ at $30{ }^{\circ} \mathrm{C}$. Peaks were detected at 260 and $365 \mathrm{~nm}$. The standards were injected under the same conditions.

\section{Acute toxicity studies}

Acute oral toxicity of the test extracts was carried out on Swiss albino mice of both sexes, as per the Organization for Economic Co-operation and Development (OECD) guidelines (Guideline 423 adopted on December, $17^{\text {th }} 2001$ ), as slightly modified by Hussain et al [11]. Swiss albino mice of both sexes were randomly divided into 7 groups ( $n=6 ; 3$ males +3 females).

The control group received saline $(0.9 \% \mathrm{NaCl})$, while the other groups received one of 2 doses (300 and $2000 \mathrm{mg} / \mathrm{kg}$ ) of the test samples (PAE, $\mathrm{CAE}$ and GE). The mice were observed for $4 \mathrm{~h}$ after administration of the test sample, and then once daily for the next 14 days to record any signs of toxicity (diarrhea, lethargy, convulsions and/or weight loss).

\section{Acetic acid-induced writhing test}

The effect of the extracts on acetic acid-inducing writhing in mice was determined as described by Koster et al [12]. The experiment was performed on 42 male mice divided into 7 groups $(n=6)$. Pain was induced by intraperitoneal injection of $0.6 \%$ acetic acid. After $30 \mathrm{~min}$, the animals were treated with two doses of the test samples: 1000 and $500 \mathrm{mg} / \mathrm{kg}$ for PAE and CAE, and 100 and $50 \mathrm{mg} / \mathrm{kg}$ for GE. The positive control groups received the standard drugs Indomethacin ${ }^{\circledR}$ (10 $\mathrm{mg} / \mathrm{kg})$ and Aspirin ${ }^{\circledR}(50 \mathrm{mg} / \mathrm{kg})$. The negative control group received saline $(0.9 \% \mathrm{NaCl})$. All test samples were given orally to the animals at the dose of $10 \mathrm{~mL} / \mathrm{kg}$. Contractions were counted for 10 min beginning with a 5-min latency period after injection. The analgesic potential (PAA) was calculated as shown in Eq 1.

$\mathrm{PAA}(\%)=(\mathrm{Nc}-\mathrm{Nt}) / \mathrm{Nc} \times 100$

where $N c$ and $N t$ are the mean number of writhes in the negative control and test groups, respectively.

\section{Anti-inflammatory effect: hind paw edema assay}

The anti-inflammatory effects of the extracts were determined using the carrageenan-induced paw edema test adapted from Winter et al [13]. Seven groups of mice (6 male mice/group) were used. Edema was induced by dermal injection of $25 \mu \mathrm{L}$ of $1 \%$ carrageenan suspension (in saline) into the plantar surface of the left hind paw of mice. The test substances, saline and reference drugs (Indomethacin and Diclofenac Sodio) were administered orally $1 \mathrm{~h}$ earlier. Thirty minutes after injection, the mice were sacrificed via diethyl ether inhalation, after which the hind paws were excised and weighed. The edema level (L) and edema reduction (OR) were calculated as indicated in Eq. 2 and Eq.3, respectively.

$L(\%)=(L P W-R P W) / R P W \times 100$

where $R P W$ and $L P W$ are right paw and left paw weights, respectively.

OR $(\%)=($ OC-OT $) / O C \times 100$

where $O C$ and $O T$ are edema reductions in control and test groups, respectively.

\section{Statistical analysis}

Data are expressed as mean \pm SEM $(n=6)$. Statistical analysis was carried out using analysis of variance (ANOVA), followed by Tukey test. Differences were considered significant at $p<$ 0.05. All statistical tests were done using STATISTICA software.

Trop J Pharm Res, September 2020; 19(9): 1897 


\section{RESULTS}

\section{Phytochemical profiles}

Phytochemical screening was carried out to compare the field-grown mother plant and in vitro-grown callus cultures with respect to composition of secondary metabolites. As shown in Table 1, flavonoids and saponins were present in both extracts, while tannins and glycosides were present only in PAE. Alkaloids and terpenoids were absent in both extracts.

\section{Phytochemical profile of Asteriscus graveolens}

The HPLC analysis of GE revealed the presence of various phenolic compounds (Figure 1). These comprised one phenolic acid, trans-cinnamic acid, and a total of eleven flavonoids, namely myricetin and its O-glucoside derivative, luteolin and its glycosides (cynarosid, orientin and isoorientin); rutin (diglycoside of quercetin), hyperoside (3-O-galactoside of quercetin), and apigenin and its C-glycosylated derivatives (vitexin and iso-vitexin).

\section{Acute oral toxicity}

No mortality and no signs of toxicity were recorded in animal groups during the observation period. Thus, none of the test samples, including aqueous extracts from mother plant and callus cultures of Asteriscus graveolens as well as the glycosidic extract, was toxic (LD ${ }_{50}>2000 \mathrm{mg} / \mathrm{kg}$ ) [14].

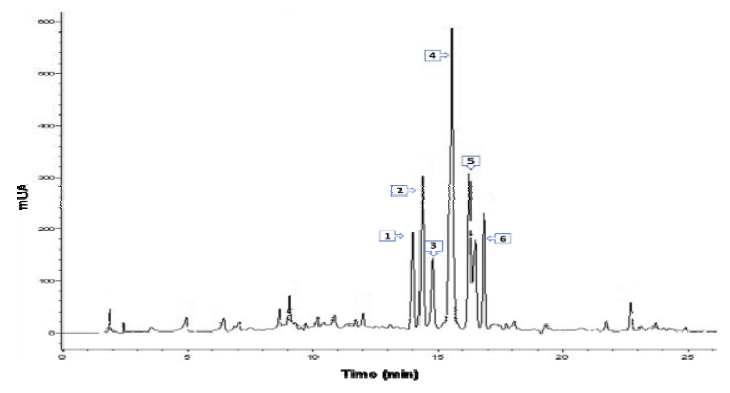

Figure 1: HPLC chromatogram of Asteriscus graveolens extract (GE) at $260 \mathrm{~nm}$. (1= apigenin; $2=$ orientin; 3 = iso-orientin; 4 = vitexin; 5 = iso-vitexin; 6 = myricetin-O-glucoside)

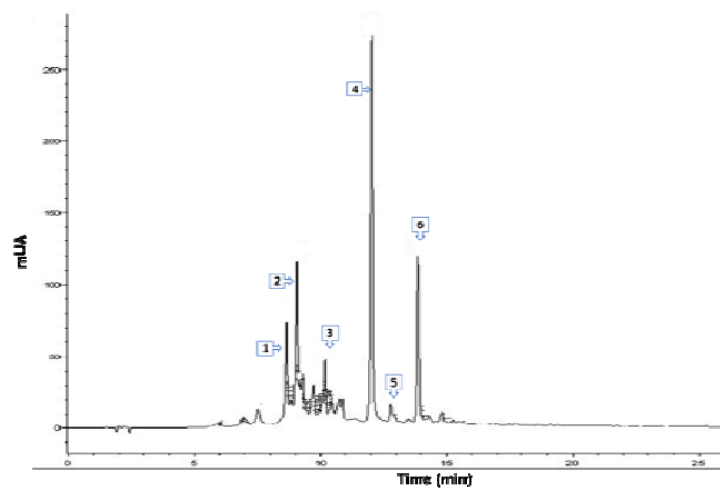

Figure 2: HPLC chromatogram of Asteriscus graveolens extract (GE) at $365 \mathrm{~nm}$. (1 = Rutin; 2 = cynaroside; 3 = hyperoside; 4 = myricetin; 5 = luteolin; $6=$ trans-cinnamic acid)

\section{Analgesic effects of extracts}

Oral administration of all extracts at all doses resulted in significant peripheral analgesic effects in the acetic acid-induced writhing test, when compared to the control group which received saline only $(p<0.001)$. All the extracts except the low-dose GE $(50 \mathrm{mg} / \mathrm{mL})$ inhibited acetic acid-induced chemical pain with the same efficiency as the reference drug Aspirin $^{\circledR}(p<$ 0.05; Table 2).

\section{Anti-inflammatory effect}

The results in Table 3 indicate that all test samples and reference drugs significantly reduced hind paw edema in mice, when compared to the negative control group ( $p<$ $0.001)$. The highest effects were observed at the higher doses (1000 mg/kg for CAE and PAE, and $100 \mathrm{mg} / \mathrm{kg}$ for GE). It is important to note that there was no significant difference in effect between CAE and PAE.

\section{DISCUSSION}

Despite the various medicinal uses of Asteriscus graveolens in traditional medicine, there are limited studies on this species, especially from pharmacological and toxicological perspectives.

Table 1: Phytochemical compositions of aqueous extracts of Asteriscus graveolens (mother plant) and callus culture

\begin{tabular}{lcccccc}
\hline Extract & Flavonoids & Tannins & Saponins & Glycosides & Terpenoids & Alkaloids \\
\hline PAE & + & + & + & + & - & - \\
CAE & + & - & + & - & - & - \\
\hline
\end{tabular}

PAE: whole plant extract; CAE: callus extract; +: present; -: absent 
Table 2: Analgesic effect of aqueous extracts of Asteriscus graveolens (whole plant and callus culture) and glycosidic extract, on acetic acid-induced pain in mice

\begin{tabular}{lccc}
\hline Group & Dose $\mathbf{( m g / k g )}$ & $\begin{array}{c}\text { Abdominal } \\
\text { constrictions }(\mathbf{n})\end{array}$ & PAA (\%) \\
\hline Negative control & - & $39 \pm 0.30^{\$ \$ \$}$ & - \\
Aspirin (reference 1) & 50 & $15.50 \pm 0,95^{\star * *}$ & 60.26 \\
Indomethacin (reference 2) & 10 & $12.17 \pm 0,13^{* * *}$ & 68.80 \\
PAE & 1000 & $14.17 \pm 0.27^{* * *}$ & 63.68 \\
PAE & 500 & $19.50 \pm 0.53^{* * *}$ & 50.00 \\
CAE & 1000 & $16.33 \pm 0.66^{* * *}$ & 58.12 \\
CAE & 500 & $18.33 \pm 0.14^{* * *}$ & 52.99 \\
GE & 100 & $14.17 \pm 0 . .5^{\star * *}$ & 63.68 \\
GE & 50 & $22.67 \pm 0.79^{\star * \star \$ \$}$ & 41.88 \\
\hline
\end{tabular}

PAE: Whole plant extract; CAE: callus extract; GE: glycosidic extract. Values are expressed as mean \pm SEM. (n $=6$ ); ${ }^{\star} p<0.05$ compared to negative control; ${ }^{* \star} p<0.01 ;{ }^{* \star *} p<0.001 ;{ }^{\$} p<0.05$, compared to aspirin; ${ }^{\$ \$} p<0.01$; $\$ \$ \$ p<0.001$ (one-way ANOVA, Tukey test)

Table 3: Anti-inflammatory activity of aqueous extracts of Asteriscus graveolens (mother plant and callus cultures) and glycosidic extract on carrageenan-induced paw oedema in mice

\begin{tabular}{lcccc}
\hline Group & $\begin{array}{c}\text { Dose } \\
(\mathbf{m g} / \mathbf{k g})\end{array}$ & $\begin{array}{c}\text { Weight of the paw } \\
\mathbf{e d e m a}(\mathbf{m g})\end{array}$ & Edema & Edema reduction \\
\hline Negative control & - & $73.20 \pm 1,07^{\$ \$ \$}$ & 60.01 & - \\
Indomethacin & 10 & $14.73 \pm 1.78^{\star * *}$ & 11.36 & 81.07 \\
Sodium diclofenac & 10 & $13.78 \pm 0.75^{\star * *}$ & 11.29 & 80.85 \\
PAE & 1000 & $17.77 \pm 1.45^{\star * *}$ & 16.09 & 73.19 \\
PAE & 500 & $51.50 \pm 1.56^{* \star \$ \$}$ & 40.15 & 33.07 \\
CAE & 1000 & $23.44 \pm 2.63^{\star * *}$ & 18.30 & 69.51 \\
CAE & 500 & $49.07 \pm 2.02^{* \star \$ \$}$ & 38.27 & 36.21 \\
GE & 100 & $21.40 \pm 0.80^{* * *}$ & 17.00 & 71.67 \\
GE & 50 & $24.82 \pm 1.02^{* * *}$ & 17.39 & 71.00 \\
\hline
\end{tabular}

Values are expressed as mean \pm SEM $(n=6) ;{ }^{*} p<0.05$, compared to negative control; ${ }^{* \star} p<0.01 ;{ }^{* \star *} p<0.001$; ${ }^{\$} p<0.05$, compared to indomethacin; ${ }^{\$} p<0.01 ; \$ \$ p<0.001$ (one-way ANOVA, Tukey test)

Therefore, it was deemed necessary to investigate the pharmacological properties of extracts of this plant. Phytochemical screening of Asteriscus graveolens aqueous extracts revealed similarities in flavonoid and tannin contents between PAE and CAE. This is not surprising since the capacity of plant cells, organelles and tissue cultures to produce and accumulate many of these bioactive chemical compounds in the same way as the wild-grown mother plants, has been recognized since the establishment of plant tissue cultures [15]. The appearance of saponins in callus cultures of Asteriscus graveolens might be linked to the presence of specific plant growth regulators. Hanafy et al. [16] have demonstrated a strong relationship between increased saponin production in callus tissue cultures and the amounts of auxins and cytokinins, particularly kinetin, added to the culture media.

The glycosidic extract (GE) was subjected to HPLC analysis in order to identify the phenolic compounds present in the plant. Only one phenolic acid and twelve flavonoids were detected. Similarly, a study has reported the presence of myricetin and luteolin in Asteriscus graveolens [5].
Results from acute toxicity tests on all extracts revealed that this plant is safe for oral use. These results are consistent with the findings in a previous study on the same species [6]. This might be due to the absence of toxic compounds such as alkaloids, on one hand, and the presence of substances with hepatoprotective properties, such as luteolin, on the other hand [17].

The acetic-acid induced writhing and the carrageenan-induced paw oedema tests were used to ascertain the basis for the traditional use of this plant as a remedy for analgesic and antiinflammatory ailments. Results indicate that all extracts of Asteriscus graveolens, whether from parent plant or callus extracts, mitigated chemically-induced pain and inflammation.

These pharmacological effects may be largely due to their richness in phenolic compounds, especially flavonoids which are known to be strong anti-inflammatory and/or analgesic agents [18]. The well-known mechanism of action of these compounds involves inhibition of cyclooxygenases (COX1 and COX2) [19]. These 
two isozymes catalyze the conversation of arachidonic acid to prostaglandins. Thus, their inhibition results in relief of the symptoms of pain and inflammation. In this study, most of the Asteriscus graveolens flavonoids identified through HPLC have been studied for their pharmacological effects. The flavone luteolin, and its glucosides modulate the expressions of inflammatory mediators such as IL-6, IL-1 $\beta$, IL-6, TNF- $\alpha$, iNOS, CD86, and the protein expressions of p-STAT3-ser727 and p-STAT3-tyr705 [21,22]. Apigenin, vitexin and its isomer isovitexin exhibit analgesic and anti-inflammatory effects in various pathways [22,23].

Myricetin may be the responsible for most of the observed analgesic effect of the extracts. Indeed, this flavonol has been shown to exert important analgesic effect on acetic acid-induced writhing model by reducing the amount of PGE2 [24]. Moreover, recent studies demonstrated that low concentrations of myricetin reduced the excitability of dorsal root ganglion (DRG) neurons in a neuropathic pain model, thereby modulating the transmission of pain sensation [25]. In contrast, quercetin-3-rutinoside "rutin" displayed peripheral and central anti-nociceptive properties by targeting opioid receptors [26].

\section{CONCLUSION}

Asteriscus graveolens is, without any doubt, a plant with promising medicinal potential, as revealed by its high analgesic and antiinflammatory effects. It interesting that the callus extract produced effects similar to those of the adult plant extract. This could pave the way for the in vitro production of the bioactive phytochemicals responsible for the observed beneficial properties, with the prospect of using them to replace non-steroidal anti-inflammatory drugs (NSAIDs), which are associated with adverse side effects. Studies are currently ongoing to investigate the underlying bioactive compounds responsible for the pharmacological effects of Asteriscus graveolens, with a view to enhancing their production in callus cultures using biotechnological techniques.

\section{DECLARATIONS}

\section{Acknowledgement}

The authors are thankful to the Research and Development Center (CRD-SAIDAL) for providing animals and some tools and reagents used in carrying out toxicity, analgesic and antiinflammatory tests.

\section{Conflict of interest}

No conflict of interest is associated with this work.

\section{Contribution of authors}

We declare that this work was done by the authors named in this article and all liabilities pertaining to claims relating to the content of this article will be borne by the authors.

\section{Open Access}

This is an Open Access article that uses a funding model which does not charge readers or their institutions for access and distributed under the terms of the Creative Commons Attribution License (http://creativecommons.org/licenses/by/ 4.0) and the Budapest Open Access Initiative (http://www.budapestopenaccessinitiative.org/rea d), which permit unrestricted use, distribution, and reproduction in any medium, provided the original work is properly credited.

\section{REFERENCES}

1. Ozenda P. Flore du Sahara Septentrional et Central, CNRS, Paris, 1958.

2. Chehma A. Catalogue des plantes spontanées du Sahara septontrional algérien. Ed. Dar Elhouda, Ain M'ilia, 2006.

3. Cheriti A, Saad A, Belboukhari N, Ghezali S. The essential oil composition of Bubonium graveolens (Forsk) Maire from the Algerian Sahara. Flavour Fragr J 2007; 22: 286-288.

4. Nasim SA, Junaid A, Kapoor R, Khan SA. Secondary metabolites production through biotechnological intervention: A Review. Emir J Food Agric 2010; 22(3): 147-161.

5. Ramdane F, Essid R, Mkasmini K, Hammami M, Fares $N$, Hadj Mahammed M, El Ouassis D, Tabbene O, Limam F, Ould Hadj M. Phytochemical composition and biological activities of Asteriscus graveolens (Forssk) extracts. Process Biochem 2017; 56: 186-192.

6. Melekmi N, Saad A, Belboukhari N, Cheriti A. Antimicrobial activity of the essential oil of Bubonium graveolens. Annales de l'Université de Bechar 2006; 2 : 22-24

7. Touitou Y, Portaluppi F, Smolensky MH, Rensing L. Ethical principles and standards for the conduct of human and animal biological rhythm research. Chronobiol Int 2004; 21(1): 161-170

8. Murashige $T$, Skoog F. A revised medium for rapid growth and bio assays with tobacco issue cultures. Physiol Plant1962; 15: 473-497.

9. Trease GE and Evans WC. Pharmacognosy 12th Ed. Bailliere Tindal, London, 1983.

Trop J Pharm Res, September 2020; 19(9): 1900 
10. Samejo $M Q$, Sumbul A, Shah S, Memon SB, Shundrigar S. Phytochemical screening of Tamarix dioica Roxb. ex Roch. J Pharm Resea 2013; 7: 181-183.

11. Hussain $T$, Fareed $S$, Diddiqui $H$, Vijaykumar $M$, Venkateswara R. Acute and subacute oral toxicity of Tephrosia pururea extract in rodents. Asian Pac J Trop Dis 2012; 129-132

12. Koster R, Anderson M, DeBeer EJ. Acetic Acid for Analgesic screening. Federation Proceedings 1959; 18 : 412-417.

13. Winter CA, Risley EA, Nuss GW. Carrageenan induced oedema in hind paw of the rat as an assay for antiinflammatory drugs. Proc Soc Exp Biol Med 1962; 111:544-547.

14. Whitehead A, Curnow R. Statistical Evaluation of the fixed-dose procedure. Food Chem Toxicol 1992; 30(4): 313-324

15. Baskaran $P$, Singh S, Staden JV. In vitro propagation, proscillaridin A production and antibacterial activity in Drimia robusta. Plant Cell Tissue Organ Cult. 2013; 114: 259-267.

16. Hanafy M, Lobna M, Abou-setta. Saponins Production in Shoot and Callus Cultures of Gypsophila Paniculata. J Appl Sci Res 2007; 3(10): 1045-1049.

17. Bigoniya $P$, Singh $P$. Hepatoprotective activity of luteolin isolated from A. millefolium on CCl4 intoxicated rat. Int $J$ Ind Med Plants 2013, 46(4): 1477-1486

18. Verri WA, Vicentini $F$, Baracat $M M$, Georgetti $S R$, Cardoso RDR, Cunha TM, Ferreira $S H$, Cunha $F Q$, Foesca MJV, Casagrande R. Flavonoids as antiinflammatory and analgesic drugs: mechanisms of action and perspectives in the development of pharmaceutical forms. Stud Nat Prod Chem 2012; 36: 297-330
19. Ribeiro D, Freitas M, Tomé SM, Silva AMS, Laufer S, Lima JLF, Fernandes E. Flavonoids Inhibit COX-1 and COX-2 Enzymes and Cytokine/Chemokine Production in Human Whole Blood. Inflammation. 2014; 38: 858-370.

20. Jang S, Kelley KW, Johnson RW. Luteolin reduces IL-6 production in microglia by inhibiting JNK phosphorylation and activation of AP-1. Proc Natl Acad Sci USA 2008; 105 (21): 7534-7539.

21. Wang S, Cao M, Xu S, Zhang J, Wang Z, Mao X, Yao X, Liu C. Effect of luteolin on inflammatory responses in RAW264.7 macrophages activated with LPS and IFN-Y. J Funct Foods 2017; 32: 123-130.

22. He M, Min JW, Kong WL, Li JX, Peng BW. A review on the pharmacological effects of vitexin and isovitexin. Fitoterapia 2016; 115: 74-85.

23. El Shoubaky GA, Abdel-Daim M, Mansour MH, Salem EA. Isolation and Identification of a Flavone Apigenin from Marine Red Alga Acanthophora spicifera with Antinociceptive and Anti-Inflammatory Activities. J Exp Neurosci 2016; 10: 21-29. Doi:10.4137/JEN.S25096.

24. Tong Y, Zhou XM, Wang SJ, Yang Y, Cao YL. Analgesic activity of myricetin isolated from Myrica rubra Sieb. et Zucc. Leaves. Arch Pharm Res 2009; 32(4): 527-533.

25. Hagenacker T, Hillebrand I, Wissmann A, Büsselberg D, Schäfers M. Anti-allodynic effect of the flavonoid myricetin in a rat model of neuropathic pain: Involvement of $\mathrm{p} 38$ and protein kinase $C$ mediated modulation of Ca2+ channels. Eur J Pain 2010; 14: 992-998

26. Selvaraj S, Kaliamurthi G, Thirungnasambandam $R$, Vivekanandan L, Balasubramanian T. Anti-nociceptive effect in mice of thillai flavonoid rutin. Biomed Environ Sci 2014; 27 (4): 295-299. 